\title{
Looking "out of place": analysing the spatial and symbolic meanings of dementia care settings through dress
}

\author{
By Christina Buse ${ }^{1} \mathcal{E}$ Julia Thigg ${ }^{2}$
}

\begin{abstract}
The article explores how clothing exposes - and troubles - the ambiguous location of care homes on the boundaries of public/private, home/ institutional space. It deploys a material analysis of the symbolic uses and meanings of dress, extending the remit of the new cultural gerontology to encompass the "fourth age," and the lives of older people with dementia. The article draws on an ESRC-funded study "Dementia and Dress," conducted in the United Kingdom (UK), which explored everyday experiences of clothing for people with dementia, carers and careworkers, using ethnographic and qualitative methods. Careworkers and managers were keen to emphasise the "homely" nature of care homes, yet this was sometimes at odds with the desire to maintain presentable and orderly bodies, and with institutional routines of bodywork. Residents' use of clothing could disrupt boundaries of public/private space, materialising a sense of not being "at home," and a desire to return there.

${ }^{1}$ Christina Buse, School of Sociology and Social Policy, University of Leeds, Leeds, UK

${ }^{2}$ Julia Twigg, School of Social Policy, Sociology and Social Research, University of Kent, Kent, UK
\end{abstract}


International Journal of Ageing and Later Life

Keywords: care homes, space, place, dementia, public/private, dress, embodiment.

\section{Introduction}

Dress mediates our material and embodied relationships to space and place. It is shaped by the meanings and conventions of particular social spaces, but also has transformative qualities (Hockey et al. 2013), materialising transitions across spatial boundaries. In this article, we use dress as a "material lens" (Chapman 2006) for understanding the meanings and social relations of one particular space - the dementia care home. Care homes occupy a particularly ambiguous position at the boundaries of public/ private space, home/not home. We explore how dress illuminates the contested meanings of this space for residents with dementia and for staff, and materialises a "desire to be elsewhere" (Potvin 2009).

The article begins by briefly summarising sociological and anthropological literature on changing meanings and the representations of "the care home," and their relation to ideals of home and hospitality. It then goes on to review research on dress, space and place. These issues are then further explored in relation to the findings of the ESRC-funded "Dementia and Dress" study. Several key themes are drawn out. Firstly, the article explores the role of clothing in defining public/private boundaries within the care home, and how residents with dementia negotiate - and subvert - these boundaries. Following this, we examine the meaning of "dressing up and going out" as a dress practice which often diminishes following transitions to care, but is re-appropriated in the context of the "care home party." The final theme explores the role of clothing in challenging the meaning of care settings as "home," and expressing residents' desire to return home at an embodied level. The concluding discussion draws together implications for understandings of dress and its relation to space and place, as well as wider implications for cultural understandings of ageing and the "fourth age."

\section{Conceptualising the Care "Home": Changing Meanings of Space and Place}

Glenda Laws (1997) states that: "age relations are constituted in, mediated by, and constrained by space" (98). She argues for a "spatiality of age 
relations" which recognises the mutual constitution of age, space and place that is both material and symbolic. Spaces are "age graded" and access to and mobility across spaces shifts throughout the life-course, with old age marginalised into "discrete spaces" (91). This is particularly apparent with age-segregated spaces such as the care home. The care home has its roots in the poorhouses of the 19th century. The ending of the Poor Law in 1948 in England saw the emergence of specialist care homes for older people (Bland 1999; Peace et al. 1997). Since then, institutional care provision has shifted, moving from the domain of local authorities to the private and voluntary sectors.

The dominant discursive construction of care homes in the post-war era in the UK has been in terms of home. Care providers have deployed both the physical features and symbolic ideals of "home" to make care homes more appealing - representing them as "homely" and as a "home away from home" (Hockey 1989). Home represents both a physical space and a "state of being" - a sense of "being at home in the world" (Jackson 1995), and of belonging (Mallet 2004). Western concepts of the ideal home focus on freedom, security and privacy, constructing the home as a haven (Chapman \& Hockey 1999), which can shut out the outside world (Allan \& Crow 1989), in which individuals can express their identities, their memories and biographies, through the symbolic use of material objects (Blunt \& Dowling 2006).

However, despite the use of the term "home," it is argued that these spaces in fact have little in common with the private domestic world (Hockey 1999). The lack of autonomy and privacy often experienced in care settings is incompatible with the ideal of home, as routines of bodywork, and the co-presence of other residents and staff mean that these spaces are never wholly private (Higgins 1989). Furthermore, loss of material possessions during the transition to care disrupts embodied connections to memories and identity (Fairhurst 1999; Mountain \& Bowie 1992). Reflecting this, care and nursing homes have been described as liminal spaces or "non-places" associated with dislocation and transience, devoid of meaning and connection (Reed-Danahey 2001). In terms of the meaning of care homes to residents, qualitative research indicates mixed findings. Whilst sometimes likened them to their home (Higgs et al. 1998: 202), more often residents have described care homes as "homey" but 
International Journal of Ageing and Later Life

"it ain't home" (Wiersma \& Dupuis 2010: 281), sometimes as akin to a "hotel" (Gubrium 1995: 35), or even a "prison" (Gubrium 1993: 146).

The design of spaces for old age is changing, however, reflecting changing concepts of ageing and the life-course, and the growing emphasis on older people as healthy and active consumers (Laws 1997). A recent UK government commission called for a reinvention of the care home model to create "places of laughter and light" which are more appealing to the "rock and roll generation" of baby boomers (Bingham 2013). As in the healthcare sector more generally (Bromley 2012), the design of care homes is increasingly drawing inspiration from the commercial and hospitality sectors, and the "hotel model." This model of care may be a more positive one, since it emphasises the rights, choices and privacy of older residents as active consumers, rather than passive recipients of care (Bland 1999). However, it has been suggested that smaller, more "homely" care units may be better suited to the care of people with dementia (Verbeek et al. 2009), with new initiatives like the "Green House Project" aiming to provide an environment which is not merely "home-like," but offers a "real home," one that emphasises privacy, autonomy and intimacy in design and organisational practice (Scher 2013).

\section{Clothing and Spatial Divisions}

Dress is "situated bodily practice," inscribed by the norms of particular social spaces, and boundaries between public and private spheres (Entwistle 2001). In turn, dress is part of the material and cultural practices which help produce particular social spaces, and "define the space as public or private" (Appleford 2015: 1). Dress lies at the interface between our intimate experience of our bodies and the public realm (Entwistle 2000). It is part of the "front" we put on and the public self we present (Goffman 1969). Making everyday decisions about dress involves consideration of the context we are dressing for, and how we would like to be perceived by a particular audience (Banim et al. 2001). Dress is also part of the micro order of social spaces, and dressing inappropriately for a particular space can incur moral judgements and sanctions (Entwistle 2000). 
In contrast, private spaces such as the home are described as "safe spaces," free from the scrutiny of the public gaze, where one might express private aspects of the self through dress (Banim et al. 2001). Norms of dress are more relaxed in this sphere, emphasising comfort, ease and softness, reflected in particular forms of dress such as slippers, dressing gowns and casual wear (Twigg 2000). Rituals of changing clothes are part of the "boundary work" which marks transitions between home/work, public/ private spheres; and shedding work clothing embodies a sense of "coming home" (Nippert-Eng 1996).

These public/ private distinctions of dress are both classed and gendered. There is a long history of research exploring the use of fashion - particularly women's dress - to convey class and status within the public realm (e.g. Simmel 1904/1974; Tönnies 1887/2004; Veblen 1899/1994). In contemporary Britain, spatial demarcations of dress continue to constitute class and gender distinctions (Appleford 2013). For instance, in recent media coverage, working class women were derided for wearing pyjamas in public space, breaking codes of formal/informal, public/private dress (Appleford 2015). Women's bodies and dress are particularly visible - coded in terms of display, as objects "to be looked at"; and women experience greater body consciousness in public spaces (Entwistle 2000). The desire to stand out and the pleasure of "dressing up" are always in tension with a sense of vulnerability, the fear of "giving out the wrong signals" (Tseëlon 1995: 31). This is heightened in particular spatial contexts, for instance whilst walking in urban spaces at night, where women often deploy strategies of dress to manage their bodies in such a way that they do not attract attention (Entwistle 2001).

Research on the interrelation of ageing, dress and spatiality is more limited. However, studies of older women, clothing and embodiment highlight changing meanings of visibility in later life. The older female body is described as both invisible and hyper-visible (Woodward 1999, 2006). Older women incur sanctions for wearing outfits judged "too young," too revealing or sexualised (Hurd Clarke 2011; Twigg 2013). At the same time, older women frequently describe themselves as becoming "invisible" in public space - for some this is experienced negatively in terms of loss of attractiveness, while for others, invisibility represents freedom from the public gaze. However, this marginalisation may be resisted, for instance, 
International Journal of Ageing and Later Life

women in the "red hat society" challenge invisibility by dressing up in brightly coloured, eye-catching attire (Yarnal et al. 2011).

These discussions of the possibilities of dress for resisting invisibility and renegotiating public space tend to focus on the "young old." However, dress takes on particular significance in relation to the cultural imaginary of the "fourth age," which is associated with vulnerability, loss of agency and "feared old age," intertwined with cultural meanings of dementia and frailty (Gilleard \& Higgs 2010, 2014). Public "slippages of dress" such as tears, stains or drooping hems take on new significance in this context, suggesting mental or moral failure (Twigg 2013). Policing one's dress becomes a means of staving off the threat of dereliction, and with it exclusion from public life. This becomes increasingly challenging in the case of dementia, where the ability to maintain appearance and dress can be diminished as the condition progresses (Baldelli et al. 2007; Beck et al. 1991). Keady and Keady (2005) relate how memory problems can lead to embarrassing public failures of dress, which incur particular sanctions in light of the stigma associated with the condition, invoking images of "dementia patient" (Twigg 2010: 228). Nonetheless, we suggest that people with dementia can still renegotiate spatial meanings and boundaries through dress, exploring this through our analysis of dress practice in the care home.

\section{Methodology}

The article draws on an ESRC-funded UK study, Dementia and Dress, which explored the significance of clothing and dress in the daily lives of people with dementia, their carers and careworkers using ethnographic and qualitative approaches. The research was conducted across three care homes in Kent, and with people with dementia and family carers living in their own homes. The sample included 32 case studies of people with dementia: 15 living in their own homes and 17 in the care home settings, selected purposively to incorporate variation in terms of socio-economic background, and stage of dementia (from mild to severe). In terms of gender, nine men and 23 women with dementia took part in the study. There were particular challenges recruiting men in the care home settings - only four care home participants were male - which reflects the lower 
proportion of male care home residents nationally (ONS 2014), and also the challenges of recruiting men to a study about dress (Lomas 2000). While the sample roughly corresponds to proportions among the general population, with around two-thirds women to one-third men with dementia (Alzheimer's Society 2014), it means that our analysis of men's dress in the care home context is more limited.

The study also included interviews and observations with family carers and relatives of participants with dementia ( 29 in total). In addition, 28 members of care home staff were interviewed; careworkers (generally the person's keyworker or someone regularly involved with their care), managers, activities workers and laundry workers. Interviews and observations were also conducted with two clothing companies. While around half family carers interviewed were male, only two careworkers in the sample were male, reflecting the gendered nature of the caring profession.

The three care homes were selected to encompass variation in ownership, design and practice, and were also spatially distinct. The first was a spacious, purpose built care home for people with dementia, run by a voluntary sector organisation. The second was a small converted detached house, run by a small business, specialising in the care of older people with dementia. The third was a nursing home run by a private health care organisation, situated within a converted stately home, with a separate dementia unit. In the UK, care homes may be "voluntary" (run by charitable non-profit organisations), "private": (run by private organisations, small businesses or individuals for profit); or "local authority" (run by the social services department), although this is now less common (Age UK 2014). Within these different types of care home, care may be self-funded, funded by the local authority or National Health Service (NHS) "Continuing Care." Residents at the first two care homes (which were priced at around the national average) were mainly local authority funded, while at the third - more expensive - nursing home, many residents were selffunded. This has implications in terms of class; and the third care home had a more middle class profile, while the other two care homes had a larger proportion of participants from working class and lower middle class backgrounds.

Data were gathered using ethnographic and qualitative methods, including innovative visual and sensory approaches involving "wardrobe 
International Journal of Ageing and Later Life

interviews" (Banim \& Guy 2001: 218) with people with dementia, using the clothing in their wardrobes to prompt discussion. A range of clothes, fabrics, images and photographs were used as visual and sensory prompts in interviews and reminiscence groups (Bartlett \& O'Connor 2010). We also conducted observations, which facilitated the inclusion of people with more advanced dementia, who found verbal communication challenging (Hubbard et al. 2003). Observations were qualitative and unstructured, taking place in the public areas of the care homes, and included observing: informal discussions of dress among careworkers and residents; non-verbal responses to clothing and interactions with dress; assistance with dress; the location of dress within care routines at different times of day.

Data were analysed using thematic analysis. Initial analysis took place as part of the writing up of field-notes after each research visit, identifying possible themes and "puzzles." Formal analysis began with a careful reading and re-reading of transcripts and fieldnotes, noting down emergent themes and concepts. A list of themes was then developed collaboratively by the research team, and used to code transcripts and fieldnotes, assisted by NVivo qualitative software.

\section{Dress and the Boundaries of Public/Private Space}

Care homes are complex spaces, ambiguously positioned in terms of public/private boundaries (McColgan 2005; Nord 2011). These ambiguities are reflected in and exposed by dress, for example, in the simultaneous presence of both slippers and handbags that we observed in care home lounges (Buse \& Twigg 2014): slippers signify ease, comfort and being "at home"; while carrying a handbag is a practice associated with public space. There are also internal gradations of public/private space within care home settings, which are marked by dress (Appleford 2015). The lounge and dining areas represent the public "front" of the care home (Goffman 1969), shared with other residents and staff, and open to visitors. Within these spaces, residents were generally presented to "lounge standard" (Lee Treweek 1997) - fully dressed and groomed. However, emphasis on maintaining a publically presentable appearance in these areas was sometimes at odds with the rhetoric that care settings should represent "home": 
... how often on your day off do you knock about in your nighty all morning? [...] And it's like why shouldn't they and then there's this great big hoo-ha if we get inspected by the CQC, if someone's sitting in the front room in their pyjamas and that. Well it's their front room, they wanted to - I know there's other people here but they're fine with it and that's what they wanted to do! [Anita, care home manager]

This quotation reveals the contradiction between the idea that wearing pyjamas or a nightie is appropriate within the care home lounge because it represents "home" to residents, and the fact that it is still a public space, inhabited by other residents and visitors. Whilst pyjamas are perfectly acceptable within the private space of the home, wearing them in public is seen as breaking codes of public dress, and therefore incurs moral judgements (Appleford 2015). As the above quotation also illustrates, staff fear that moral sanctions will be directed at them, as a visible indicator of poor quality care (Ward et al. 2008), which "looks like we haven't bothered." Reflecting this, careworkers would sometimes "advise" or "guide" residents towards particular clothing choices which looked "nice" or "dignified," and discourage outfits which were loud, "clashing," or bizarre. As one careworker, Sharon, said: "I want people to look as if they look kept" and "make them look nice. I would feel terrible if somebody went out of here and said they looked awful." These ambiguities are further complicated in relation to dementia, because of issues around mental capacity and imputed wishes (Twigg 2010).

There was a gendered and classed dimension to this - an untidy appearance was sometimes seen as more acceptable in the case of working class men, interpreted as a reflection of masculine lack of interest in fashion (Kaiser 2012), and biographies of manual labour, for which everyday dress constituted overalls or casual attire rather than "proper, dressed up clothes." As care home manager Anita reflected regarding one particular resident, Bobby: "he's working class, salt of the earth, he's not over fussed, just as long as he's covered up ...," while his daughter felt that a "casual" or even "scruffy" appearance was acceptable "because it's him" - the way he had "always been."

Maintaining the public "front" of the care home also involves containing the "disruptive body of dementia" (Stirling 1995: 147), which disturbs boundaries of public and private space. This is illustrated by the case of public undressing. In Western culture, nakedness is generally confined to 
private spaces and encounters; and undressed bodies outside the norms of public space are "disturbing, disruptive and potentially subversive" (Entwistle 2000: 7). However, dementia can lower social inhibitions. This was particularly seen as problematic in times and spaces where visitors were expected, as careworker Helen said: "we just have to go round and say," "Come on, put a jumper on quickly. Hurry up," you know, "we've got visitors coming." Therefore, the undressed body had to be contained within private space, and care workers would sequester the person with dementia to a bedroom or bathroom, or hide them quickly with clothing or a blanket. Careworkers also attempted to re-establish the boundaries of private/public space, reminding residents: "you're in the lounge, everybody's looking" or "there's lots of other people in here."

In the more private or "backstage" areas of the care home, norms of dress were more relaxed, and there was less emphasis on maintaining orderly bodies (Chatterji 2006). This spatial and symbolic categorisation was given additional expression in the third, more exclusive care home, which was located in a large Victorian country house where the hall, drawing rooms and winter garden provided high ceilinged, formal spaces in which residents enacted their role as "lounge standard residents" (LeeTreweek 1997). This contrasted with the specialist dementia unit for more severely affected residents. This was located at the back of and below the main house, in the old kitchen offices. Here the spaces were smaller and lower. The regime was warmer, less formal, with a more homely atmosphere in which there was greater emphasis on "being" than "appearing" (Appleford 2015), and where inappropriate undressing would be less noticeable:

Downstairs [in the dementia unit] it wouldn't not be appropriate because people wouldn't look [...] it's expected. Do you understand? It's more tolerant [...] it's more acceptable. But up here, it's ... they stand out and unfortunately, it's sad for them [...] because they look ... you know, they look out of place, don't they? [Sharon, careworker]

This reflects the different perceptions of visibility and the public gaze in these spaces, and different constructions of "normality" (Goffman 1969). In the dementia unit no-one would look at unusual dress practice, it is regarded as "normal"; whilst in the nursing home it is subject to the stigmatising gaze of residents and visitors, and "looks out of place." 
Inappropriate undressing was not only regarded as symptomatic of dementia, but was seen as pointing up the ambiguous spatial meaning of care homes. One careworker, Michael suggested: "maybe it's something you do indoors ... I suppose that's part of it; they're in their home. They do what they would do at home." Similarly careworker Helen stated: "they might think they're in their own home doing it. Which they might just walk around with just their knickers on or their vest on." Inappropriate undressing was thus felt to reflect the re-enactment of embodied practices of being "at home," and was to some extent normalised in these accounts. On the other hand, such behaviour was judged to be misplaced within the more public context of the care home, reflecting disorientation and confusion. The fact that such behaviour was considered appropriate "at home" but not "here" exposes the embodied limits of interpreting care settings as home.

Whilst some areas of the care home offer a greater degree of privacy, there is still a lack of truly private space (Nord 2011). Even bedrooms are compromised by routines of care, disrupting "space privacy" and "body privacy" (Wiersma \& Dupuis 2010). This has implications for dress, since clothes enable us to manage the public front we present to the world, concealing bodily flaws or frailty (Twigg 2000). However, in institutional contexts, the ability to maintain a public "front" is diminished (Goffman 1961). One family carer described how, as a result of impaired hearing, her Nan could not hear careworkers knocking, and "doesn't like the fact that they just open the door," and "she might be in the middle of getting dressed or something." The degree of privacy available to residents varies according to mental and physical frailty, with those who are "aidedependent" (Gubrium 1997) accorded the least "body privacy."

Nonetheless, as found in previous studies, some residents with dementia deployed bodily strategies to re-create a private space for themselves (McColgan 2005). Such privacy is difficult to attain when the majority of the day is spent in the care home lounge (Barnes 2006). Strategies for creating privacy included utilising items of clothing and dress to redefine spatial boundaries. For instance, women with dementia would use their handbags (Buse \& Twigg 2014) or other items of dress as "territorial markers" (Harris \& Lipman 1980) to mark out "their seat," or "their space: 
International Journal of Ageing and Later Life

\begin{abstract}
She sat down on the other side of the room, adjusted the buttons on her cardigan and looked in her handbag. It reminded me of the gestures people make when they are out on their own in public, and want to appear 'occupied'. When Lillian returned, assisted by a female care worker, she was extremely annoyed to find that Colin had fallen asleep on her cardigan - she said 'how dare you fall asleep on my pillow' and yanked it out from under him. [Fieldnotes care home 2, visit 4]
\end{abstract}

This illustrates how clothing was used to mark out private "territories," and as a "prop" - a means of looking busy or purposeful when sitting alone in a public space, disguising a sense of vulnerability (Henderson 1975). We observed women with dementia who would spend hours rummaging through their handbag in the care home lounge, which provided a way to avoid talking to other residents, and a "defence against being looked at," resembling practice in public space (Tallack 2002). Men similarly used their pockets to carry reading material or photographs, which could provide a distraction from talking to other residents, and used props such as a walking stick or a newspaper to mark out "their space."

Such actions illustrate the limitations of privacy in care settings, but also suggest how dress may be used by people with dementia to enact agency at an embodied level (Hockey et al. 2013; Kontos 2004), creating a "microspatiality of privacy" around themselves, remaking personal space in public (Nord 2011: 948). These practices not only occurred in the public areas of the care home, but also extended to the bedroom. Like handbags, wardrobes represent a private, enclosed space (Woodward 2007), which may be utilised to reclaim privacy which is compromised by the public life of the care home. For example, some residents would use their wardrobes to hide jewellery and special possessions or outfits, concealed within handbags, boxes, or garment bags, as care home resident Marie described:

Oh we have to keep them in the bag so they don't pull them all out because some people sometimes think they can just raid the wardrobes, see, and you get a bit annoyed if it's all stuff you've bought [...] We've had a few rows going on about clothes!

Women with dementia were often particularly resistant to the idea of someone else doing their laundry, reflecting a reluctance to relinquish domestic roles (Hockey 1989), but also a dislike of the privacy of their wardrobes being "raided," as described above. The wardrobe could also 
become a site for defending "body privacy," and careworkers described residents with dementia - both men and women - trying to conceal soiled undergarments in their wardrobes, in an effort to avoid the shame and stigma associated with "leaky bodies" (Lawton 1998).

\section{All Dressed Up and Nowhere to Go?}

"Dressing up" is a particular form of dress practice, located within public spaces such as bars, restaurants or parties, and signifying "special occasions" (Appleford 2015; Tseëlon 1995). To an extent, the practice of dressing up is inevitably diminished on admission to care, reflecting the "desegregation" of the spheres of home/work/leisure that characterises institutional life (Goffman 1961: 17, 42). Care home residents generally wore the same outfit all day, except if their clothing was dirty or soiled. As one careworker, Yvonne, said: "in general, they usually remain in what they've chosen for the day [...] as you wouldn't get changed yourself if you were just sitting around indoors." Therefore changes of dress which mark "punctuations in the flow of everyday life" (Stov 2011: 6) are diminished, reflecting a loss of transition between different spatial contexts and identities. The person with dementia generally has one ongoing role throughout the day - that of the care home resident.

The loss of gradations of dress reflects a reduction in public life outside the care home, which becomes increasingly marked as dementia progresses. In the advanced stages of the condition, relatives and careworkers discouraged trips outside the care home, as they were felt to increase distress and disorientation. The loss of mobility and access to outdoor spaces (Laws 1997) was reflected in changes in the wardrobes of care home residents - specifically a reduction in "outdoor" or "dressed up" clothing and shoes. For instance, Mable, a woman with advanced dementia, had just one pair of sandals in addition to her slippers. Her son reflected that there was no need for additional footwear because: "I don't think she goes out that much anyway" as the more she is "out of this home, the more agitated she became." Many care home residents similarly owned just one pair of outdoor shoes, and often these were not stored in the wardrobe, reflecting their infrequent use. This loss of "going out" shoes reflected the transition to care, but also changes in the body - with spreading or swelling feet limiting possibilities for footwear. 
International Journal of Ageing and Later Life

This illustrates the interrelations between the bodies, space and dress, and their implications for constraining as well as enabling possibilities (Hockey et al. 2013).

Some residents with milder dementia, however, still went on excursions outside the care home - a transition marked by donning "outdoor" and "best" clothing. As careworker Yvonne reflected, when they go out residents should be: "dressed to go out; they've got to go out looking presentable" and "it's a special occasion for them so they want to be dressed nicely." It was often families who emphasised the importance of "dressing up" to go out; and they were understandably upset if their relative was not presented appropriately. Melissa was "hurt" and "upset" when she found her Dad in "screwed up clothing" because he had "always been smart," and felt this was particularly unacceptable "if I did want to take him out for a meal or something." This again reflects concerns about appearance as a visible indicator of the quality of care (Ward et al. 2008), but also about "the gaze" in public space. Slippages of dress which are ignored in the context of care can incur stigma and moral judgements in public. For instance, Denise complained that when she came to take her friend Lillian out from the care home, she always wore the same old "tatty" clothing, and she worried that "people seemed to look" at her pityingly. Denise said: "when you go out you want to make an effort - there's a difference between what you would wear for lounging at home and going out - but she doesn't seem to worry." Therefore, a decline in gradations of dress not only reflected a characteristic of institutional life, but also of dementia. Families of people with dementia frequently reported that they had lost the ability to dress appropriately for the occasion, failing to demarcate between indoor/ outdoor and informal/formal dress.

Despite diminished involvement in public life, dressing up takes on new meaning in the context of the care home, in relation to "institutional ceremonies" (Goffman 1961) such as the care home party. In these instances, dressing up was re-appropriated by care staff to signify a sense of occasion, and reconnect with times and spaces beyond the care home. Changing clothes not only engenders physical transformation, but also mental transformation - shedding or putting on clothes involves putting on, or taking off, particular roles and aspects of the self (Nippert-Eng 1996). Because of the sameness of everyday dress in care settings, dressing up 
conveyed a clear departure from the normal order, signifying "special occasions" such as birthdays, and calendric events such Easter, Halloween and particularly Christmas:

\footnotetext{
... I went down Christmas day and Easter day and they'd made sure she looked extra smart kind of thing, you know, which is really nice because that's what mum would like. You know, because she always dressed for special events [...] she doesn't always remember what the special event is these days [laughing] unfortunately but, you know, she knows it's something so that's really good. [Deidre, family carer]
}

Maintaining these rituals helps maintain a sense of normality and continuity with the outside world. As Deirdre says, dressing for the occasion is something her mother "would like" and "always did." Similarly, Melissa talked about how her dad, Harry, used to dress smartly at Christmas: "he would always dress up in a shirt and tie and a nice posh pair of trousers. Always make an effort." As a careworker, Sharon tried to help residents maintain these rituals, saying: "We all dress up Christmas morning. That's the first thing you put on, is your new clothes, isn't it?" Dressing up therefore provided a way of maintaining wider social rituals within the context of care, and conveying meaning to the person with dementia at an embodied level. Deirdre's mother is not always aware "what the special event is" but dressing up gives a sense that "it's something."

At one level, this dressing up practice was conducted for the benefit of residents; breaking up the monotony of institutional time, as well as evoking memories and reminiscence. Residents expressed enjoyment in doing, and wearing, "something different." On the other hand, dressing up for the occasion was also about "institutional display" (Goffman 1961: 96). Visitors were more likely to attend care homes on these occasions and were sometimes specifically invited. Therefore it was particularly important to present a "dressed up view" of the home to visitors, which demonstrates that "natural" and normal things happen there (Goffman 1961: 100):

... when Betty was $[\ldots]$ a hundred, her daughter brought in like a two-piece suit for her. And I hung it on the wardrobe [...] I made sure that lady had a bath the day before, her hair was done and everything [...] I wanted her to look nice. [...] I think it reflects on the home as well, doesn't it? [Sharon, careworker] 
International Journal of Ageing and Later Life

Therefore "dressing up" for special occasions was not only about how the person with dementia felt, but also about maintaining visible continuity for relatives, and the public front of the home.

Dressing up practice was also used to recreate a sense of place. For instance, in one home, both staff and residents dressed up for a seaside themed day - residents wore straw hats, while staff wore t-shirts, shorts or other casual apparel. Along with material props like sand, deckchairs and shells, dress was used to recreate the atmosphere of the seaside. On another occasion, careworkers wore white lace aprons to serve food to residents for a Valentine's Day dinner. The fact that staff, as well as residents, dressed up is significant here - conveying a sense that things were "different" from the normal order. As one careworker, Jo, said: "it makes the staff feel different as well. They reacted totally differently when they were wearing those." Uniforms signify institutional care and clear role distinctions between staff and residents, whilst dressing up created temporary "role release" (Goffman 1961: 90). Staff changing their dress could help transform the meaning of the space, for instance, Jo described how wearing white lace aprons evoked memories of "tea rooms when they always used to wear things like that," transporting residents and staff - to other times and places (Potvin 2009).

\section{Escaping the Care Home through Dress}

In the examples above, attempts to transform the temporal and spatial boundaries of the care home through "dressing up" were mainly orchestrated by staff. However, dress was also utilised by residents with dementia as part of expressing their "desire to be elsewhere" (Potvin 2009). This involved expressing a longing to "get on the outside" (Goffman 1961: 23), but also a desire to go home - a metaphysical place associated with comfort, familiarity and belonging (Higgins 1989). We frequently observed exchanges in which people with dementia would state that they had to get out of "this place" and "go home," which were sometimes accompanied by adjustments of dress, such as putting on a coat:

... one of the clients had [the coat] on walking around the lounge because it was hanging up along the corridor [...] she had one of those days, she didn't want to be here with these mad people. 'Will you tell me where I am?' I said, 'Well you're in a 
Looking "out of place"

nursing home.' 'Well yes, they have told me that but I don't want to be here ...' [Hannah, laundry worker]

Therefore, putting on a coat was this residents' way of conveying that she "didn't want to be here," signifying her intention to leave at a material and embodied level. One male resident would often put on his coat in the evening and start gathering up various items from around the care home lounge, putting them in his pockets or up his jumper, as though packing up to "go home."

This desire to "go home" seemed more prominent among women during our observations, perhaps reflecting their greater identification with the domestic sphere. When talking about "going home" women re-enacted gendered rituals of getting ready, asking for a comb or putting on lipstick. These rituals sometimes involved trying to adjust dress to make oneself "presentable," as the following discussion between Florence and fellow resident Mavis illustrates:

Florence started rolling up her night dress up and saying ' $I$ 'll have to do something with myself' and 'if I just do that and smarten myself up I can go'. She then held up her feet and looked at them and said 'I have been trying to put the things on so I can go. I've, I put this coat on' [indicating to a fleece jacket, worn on top of her nightdress]. Mavis said to her 'I'd zip it up, it's cold outside'. [Fieldnotes, care home 3, visit 9]

As discussed earlier, getting dressed is part of preparing the public "face" we present to the outside world, marking the transitions between public/private, indoor/outdoor space - something which is of particular significance to women. Florence is attempting to re-enact these embodied rituals by making herself presentable enough to start her journey home. While she was not in fact wearing the correct attire, her actions clearly expressed meaning and intentionality at an embodied level (Kontos 2004). These attempts to "go home" were more frequent in the evening and were sometimes explained by careworkers in terms of "sun-downing." Sundowning is defined as: "an acute increase in disorientation or deterioration in cognition, with a sudden onset of restlessness and confusion, in the late afternoon into the early evening" (Grealy et al. 2005). However, ReedDanahey (2001) argues that such behaviour also says something meaningful about the dislocation experienced in care settings. 
International Journal of Ageing and Later Life

Like putting on a coat, packing or carrying a suitcase makes a strong visual statement about the desire to leave a particular space and signifies being away from home. Careworkers described how when Florence first moved to the dementia unit, she "used to keep packing her case" because she "thought she was going home to her Mum," and would bring it into the lounge, waiting for the bus. As discussed, carrying a handbag similarly disrupts meanings of care homes as "homely" (Buse \& Twigg 2014); and handbags were often part of rituals of waiting to go home. For instance, Lillian once sat by the door for a whole day clutching her handbags and asking: "when am I going home?" and "is this all I'm taking, these two bags?" On other occasions, women would rummage through their bags, fruitlessly looking for money for the "bus fare home." These dress practices suggest experiences of the care home as a liminal space of "waiting, waiting"; imbued with a similar "limbo quality" to that of a hotel lobby or waiting room (Tallack 2002: 144). The care home was interpreted by residents as a temporary space "to be passed through" (Auge 1995: 104) and was sometimes mistaken for other transient "non-places" such as a bus stop, hospital or even a hairdressing salon.

Therefore, dress can provide a means of "appropriation and redefinition" of the spatial meanings of the care home (Rocamora 2013: 162). This not only occurred through material dress practice, but also through "dress stories" (Weber \& Mitchell 2004) which invoked narrative connections with other places - remembered, representational and imagined. Memories of place were intertwined with narratives of dressing up and going out; of "special" occasions and outfits. This is illustrated by Rita's vivid description of her "gold lamé jacket":

I used to have a lamé jacket ' $n$ all $[\ldots]$ that used to sort of light up when I was in a room, they'd all stare because it sort of shone. You how it does, lamé? [...] I liked it and I like that lamé ... it glittered, it stood out. Do get me? Sort of shone, like. It did! It's true.

Rita's account of her jacket is highly spatialised - embedded with images of being in a public space where she was the centre of attention, and her jacket "shone" causing people to "stare." She talked about this jacket to residents and staff in the care home and encouraged careworkers to refer to it in daily interactions around dress. By telling these stories, 
Rita invokes "snapshots of energy, youth, and self-importance," transcending her current embodied dependency in the care home (Hockey 1989: 205). In this account, her lamé jacket takes on the role of a "quasiobject" akin to Dorothy's ruby slippers in the Hollywood Film The Wizard of $\mathrm{Oz}$ - a fetishised object imbued with "magical" properties, which exudes a "shine" or radiance (Schiermer 2011). Other women told similar stories of youthful nights out, of swishing petticoats, silver dance shoes and towering stilettos, which were intertwined with memories of place - dancehalls, restaurants, parties and cruise ships. There was a particular focus on clothing and shoes that were "special," glamorous and impractical, impossible within the confines of their current bodily and spatial limitations.

Dressing up narratives were most frequently told by women, reflecting a particularly female pleasure and camaraderie in "dressing up and going out" (Skeggs 1997). In contrast, men's dress stories tended to focus on work clothing, evoking images of building sites, offices and market places. However, some (particularly middle class) men did tell stories about dressing up - getting a suit made "for special occasions" or wearing "patent leather shoes" for dancing, which were connected to displays of class and status: "if a man was doing his best he wore patent leather shoes." For working class women, dressing up involved a careful negotiation of attractiveness and respectability, which can be reconciled through "glamour" (Skeggs 1997). Rita recalled how "you had to have pale rouge on ... because you were common if it showed red," while a gold handbag showed you were "someone." Her dress stories carry glamour and status forward into the context of care, and care home workers described her as someone who had "enjoyed the high life" and "been quite glamorous."

Clothing narratives not only invoked residents' past temporal and spatial trajectories, but also imagined futures beyond the care home (Hockey et al. 2012), in which they were not always going to "be here." One resident, Lillian, would regularly talk about going to the dance hall that evening, and what she might wear, asking the researcher "are you going?" and "have you got a new dress?" Florence talked about her Mum waiting for her at home, and how she had made all the garments she was wearing, and would "be cross" if she wasn't properly dressed. Another 
International Journal of Ageing and Later Life

woman, Marie, stated that she was "just here until I get better" and expected to return to her old life and her "real home" again, where her fur coats would be waiting for her:

They were lovely coats $[\ldots]$ a real beaver lamb coat. A great big one that she left with me [...] I've got it at home somewhere. It should still be there.

These narratives illustrate the potential of dress for enabling "earlier identities to be revisited or released" and "future age-based identities to be accelerated or deferred" (Hockey et al. 2012). Dress not only disrupts linear temporal trajectories, but also enables a renegotiation of spatial boundaries and meanings. As argued by Jamie (2012: 71): "you are placed in landscape, you are placed in time. But within that, there's a bit of room for manoeuvre" (cited in Hockey et al. 2012). Thus, while age relations may be "constrained by space" (Laws 1997: 98), dress can provide that "bit of room for manoeuvre" - a means of escaping to other times and spaces, and revisiting the metaphysical place of "home."

\section{Conclusion}

At a time when the meanings of "the care home" are being debated and renegotiated in media, policy and academic literature, this article suggests that analysing material practice - specifically dress - can help illuminate the meanings of these spaces. In contrast to the rhetoric that care homes represent a "home from home," the dress practice of residents with dementia suggests a semi-private space, more akin to the hotel lobby. Private dress associated with being at home is difficult to reconcile with the lack of body privacy and space privacy experienced in care homes (Wiersma \& Dupuis 2010), suggesting that perhaps they can never truly be home. However, at the same time our research highlights the potential of dress for transforming meanings and experiences of dementia care, providing a means of carving out personal space and transporting residents to other places and spaces - real, remembered and imagined.

Our research therefore adds to sociological and anthropological literature exploring how older people experience everyday life in care. Rather than viewing the actions of people with dementia as merely 
symptomatic of their condition, we suggest that their behaviour conveys meaning and intention at embodied level (Kontos 2004) and indicates experiences of dislocation and loss of "home" (Reed-Danahey 2001). Previous research in this field has highlighted how care homes residents including those with dementia - may renegotiate material and symbolic meanings of these spaces through embodied practice, including the use of material objects (McColgan 2005). Our research highlights an additional element of the constitution and negotiation of everyday life in the care home - that of dress.

The article also contributes to analysis of the relationship between space and dress, and extends this to the context of the fourth age, and dementia care. As argued by Hockey and colleagues (2013), dress is embedded in experiences of life-course transition, as well as transitions between spaces and places. However, there is little specific analysis of the relationship among dress, space and old age, particularly in terms of older people who are mentally or physically frail. Therefore, our research brings together analysis of dress and space, with the "spatiality of age relations" (Laws 1997). In addition, the article highlights the significance of considering dress in relation to "representational and imagined" spaces (Rocamora 2013), and how memories and narratives of dress may "transport the embodied subject to another place and space" (Potvin 2009: 1).

Lastly, the article demonstrates how insights from the wider Cultural Turn can contribute to the analysis of deep old age. Much of the work in the new field of cultural gerontology (Twigg \& Martin 2015) focuses on the lives and experiences of younger old people, those in the Third Age, often centred on themes like consumption, representation, bodily appearance and leisure. This article demonstrates how such cultural approaches can fruitfully be extended to the context of the fourth age and to older people experiencing mental or physical frailty; and in doing so it expresses a commitment to the wider inclusions of such groups.

\section{Acknowledgements}

The article draws on a study funded by the Economic and Social Research Council of UK, Dementia and Dress, RES 062-23-3195. The authors would like to thank all study participants for their insights and support with the 
International Journal of Ageing and Later Life

project. We would also like to thank delegates at the symposium: Almost Home: Hotel, Prison, or Hospital? Cultural Representations of Long Term Care, at the 8th International Conference on Cultural Gerontology, for feedback on an earlier version of the paper.

\section{Corresponding Author}

Christina Buse, School of Sociology and Social Policy, University of Leeds, Leeds, LS2 9JT, UK. Email: C.Buse@leeds.ac.uk

\section{References}

Age UK. (2014). Factsheet 29: Finding Care Home Accommodation. London: Age UK.

Alzheimer's Society. (2014). Dementia UK (Second Edition): Overview. London: Alzheimer's Society.

Allan, G. \& Crow, G. (1989). Introduction. In G. Allan \& G. Crow (eds.), Home and Family: Creating the Domestic Space (pp. 1-13). London: Macmillan.

Appleford, K. (2013). Fashion and class evaluation. In S. Black, A. Haye, J. Entwistle, R. Root, H. Thomas \& A. Rocamora (eds.), The Handbook of Fashion Studies (pp. 102-120). London: Bloomsbury.

Appleford, K. (2015). Being seen in your pyjamas: The relationship between fashion, class, gender \& space. Gender, Place and Culture. doi: 10.1080/0966369X.2015.1013439.

Auge, M. (1995). Non-Places: Introduction to an Anthropology of Supermodernity. London: Verso.

Baldelli, M. V., Boiardi, R., Ferrari, P., Bianchi, S. \& Hunscott Bianchi, M. (2007). Dementia and occupational therapy. Archives of Gerontology and Geriatrics 44(Supplement 1): 45-48.

Banim, M., Green, E. \& Guy, A. (2001). Introduction. In A. Guy, E. Green \& M. Banim (eds.), Through the Wardrobe: Women's Relationships with their Clothes (pp. 1-18). Oxford: Berg.

Banim, M. \& Guy, A. (2001). Discontinued selves: Why do women keep clothes they no longer wear? In A. Guy, E. Green \& M. Banim (eds.), Through the Wardrobe: Women's Relationships with their Clothes (pp. 203-219). Oxford: Berg. 
Barnes, S. (2006). Space, choice and control, and quality of life in care settings for older people. Environment and Behaviour 38(5): 589-604.

Bartlett, R. \& O'Connor, D. (2010). Broadening the Dementia Debate: Towards Social Citizenship. Bristol: Policy Press.

Beck, C., Heacock, P., Mercer, S., Walton, C. G. \& Shook, J. (1991). Dressing for success: Promoting independence among cognitively impaired elderly. Journal of Psychosocial Nursing and Mental Health Services 29(7): 30-35.

Bingham, J. (2013). Rock ' $\mathrm{n}$ ' roll care homes for baby boomers. The Telegraph, 21 July. Available on http://www.telegraph.co.uk/health/ elderhealth/10192549/Rock-n-roll-care-homes-for-baby-boomers.html (Accessed: February 7, 2014).

Bland, R. (1999). Independence, privacy and risk: Two contrasting approaches to residential care for older people. Ageing and Society 19(5): 539-560.

Blunt, A. \& Dowling, R. (2006). Home. Oxon: Routledge.

Bromley, E. (2012). Building patient-centeredness: Hospital design as an interpretive act. Social Science \& Medicine 75(6): 1057-1066.

Buse, C. \& Twigg, J. (2014). Women with dementia and their handbags: Negotiating identity, privacy and 'home' through material culture. Journal of Aging Studies 30(1): 14-22.

Chapman, S. A. (2006). A 'new materialist' lens on aging well: Special things in later life. Journal of Aging Studies 20(3): 207-216.

Chapman, T. \& Hockey, J. (1999). Ideal Homes? Social Change and Domestic Life. London: Routledge.

Chatterji, R. (2006). Normality and difference: Institutional classification and the constitution of subjectivity in a Dutch nursing home. In A. Leibing \& L. Cohen (eds.), Thinking about Dementia: Culture, Loss and the Anthropology of Senility (pp. 218-239). New Brunswick: Rutgers University Press.

Entwistle, J. (2000). The Fashioned Body: Fashion, Dress and Modern Social Theory. Cambridge: Polity.

Entwistle, J. (2001). The dressed body. In J. Entwistle \& E. Wilson (eds.), Body Dressing (pp. 33-58). Oxford: Berg.

Fairhurst, E. (1999). Fitting a quart into a pint pot: Making space for older people. In T. Chapman \& J. Hockey (eds.), Ideal Homes? Social Change and Domestic Life (pp. 96-107). London: Routledge. 
International Journal of Ageing and Later Life

Gilleard, C. \& Higgs, P. (2010). Frailty, disability and old age: A reappraisal. Health 15(5): 475-490.

Gilleard, C. \& Higgs, P. (2014). Studying dementia: The relevance of the fourth age. Quality in Ageing and Older Adults 15(4): 241-243.

Gubrium, J. (1993). Speaking of Life: The Horizons of Meaning for NursingHome Residents. New York: Aldine de Gruyter.

Gubrium, J. F. (1995). Perspective and story in nursing home ethnography. In N. J. Henderson \& M. D. Vesperi (eds.), The Culture of Long Term Care: Nursing Home Ethnography (pp. 23-36). Westport, CT: Bergin and Garvey.

Gubrium, J. F. (1997). Living and Dying at Murray Manor [Expanded paperback edition]. Charlotteville, VA: University Press of Virginia.

Goffman, E. (1961). Asylums. London: Penguin.

Goffman, E. (1969). The Presentation of Self in Everyday Life. London: Lane.

Grealy, J., McMullen, H. \& Grealy, J. (2005). Dementia Care: A Practical Photographic Guide. Oxford: Blackwell.

Harris, H. \& Lipman, A. (1980). Social symbolism and the space usage in daily life. Sociological Review 28(2): 415-429.

Henderson, M. (1975). Acquiring privacy in public. Urban Life and Culture 3(4): 446-455.

Hockey, J. (1989). Residential care and the maintenance of social identity: Negotiating the transition to institutional life. In M. Jefferys (ed.), Growing Old in the Twentieth Century (pp. 201-217). London: Routledge.

Hockey, J. (1999). The ideal of home: Domesticating the institutional space of old age and death. In T. Chapman \& J. Hockey (eds.), Ideal Homes? Social Change and Domestic Life (pp. 108-118). London: Routledge.

Hockey, J., Dilley, R., Robinson, V. \& Sherlock, A. (2012). If I could turn back time? footwear, identity and the life course. Paper presented at the MICRA/The Hair and Care Project Academic Conference: Appearance, Ageing and the Life Course, University of Manchester. Available on http:// www.ihs.manchester.ac.uk/events/pastworkshops/2013/MICRA_Hair_ and_Care_Project (Accessed: May 29, 2014).

Hockey, J., Dilley, R., Robinson, V. \& Sherlock, A. (2013). Worn shoes: Identity, memory and footwear. Sociological Research Online 18(1): 20.

Higgs, P. F. D., Macdonald, L. D., Macdonald, J. S. \& Ward, M. C. (1998). Home from home: Residents' opinions of nursing homes and long-stay wards. Age and Ageing 27: 199-205. 
Higgins, J. (1989). Homes and institutions. In G. Allan \& G. Crow (eds.), Home and Family: Creating the Domestic Space (pp. 158-185). London: Macmillan.

Hubbard, G., Downs, M. \& Tester, S. (2003). Including older people with dementia in research: Challenges and strategies. Aging \& Mental Health $7(5): 351-362$.

Hurd Clarke, L. (2011). Facing Age: Women Growing Older in Anti-Ageing Culture. Lanham, MD: Rowman \& Littlefield.

Jackson, M. (1995). At Home in the World. Durham, NC: Duke University Press.

Jamie, K. (2012). Sightlines. London: Sort Of Books.

Kaiser, S. B. (2012). Fashion and Cultural Studies. London: Bloomsbury.

Keady, J. \& Keady, J. (2005). The wrong shoes: Living with memory loss. Nursing Older People 17(9): 36-37.

Kontos, P. (2004). Ethnographic reflections on selfhood, embodiment and Alzheimer's disease. Ageing $\mathcal{E}$ Society 24(6): 829-849.

Laws, G. (1997). Spatiality and age relations. In A. Jamieson, S. Harper \& C. Victor (eds.), Critical Approaches to Ageing and Later Life (pp. 90-100). Buckingham: Open University Press.

Lawton, J. (1998). Contemporary hospice care: The sequestration of the unbounded body and 'dirty dying'. Sociology of Health and Illness 20(2): 121-143.

Lee-Treweek, G. (1997). Women, resistance and care: An ethnographic study of nursing auxiliary work. Work, Employment and Society 11(1): 47-63.

Lomas, C. (2000). I know nothing about fashion. There's no point in interviewing me. In S. Bruzzi \& P. Church-Gibson (eds.), Fashion Cultures: Theories, Explorations and Analysis (pp. 363-370). Oxon: Routledge.

Mallet, S. (2004). Understanding home: A critical review of the literature. Sociological Review 52(1): 62-89.

McColgan, G. (2005). A place to sit: Resistance strategies used to create privacy and home by people with dementia. Journal of Contemporary Ethnography 34(4): 410-433.

Mountain, G. \& Bowie, P. (1992). The possessions owned by long stay psychogeriatric patients. International Journal of Geriatric Psychiatry 7(4): 285-290. 
International Journal of Ageing and Later Life

Nippert-Eng, C. (1996). Home and Work. Chicago, IL: University of Chicago Press.

Nord, C. (2011). Architectural space as a moulding factor of care practices and resident privacy in assisted living. Ageing and Society 31(6): 934-952.

ONS. (2014). Changes in the Older Resident Care Home Population between 2001 and 2011. Newport: Office for National Statistics.

Peace, S. M., Kellaher, L. A. \& Willcocks, D. M. (1997). Re-evaluating Residential Care. Buckingham: Open University Press.

Potvin, J. (2009). The Places and Spaces of Fashion, 1800-2007. Oxon: Routledge.

Reed-Danahey, D. (2001). 'This is your home now!': Conceptualizing location and dislocation in a dementia unit. Qualitative Research 1(1): 47-63.

Rocamora, A. (2013). Introduction: Spaces of fashion. In S. Black, A. Haye, J. Entwistle, R. Root, H. Thomas \& A. Rocamora (eds.), The Handbook of Fashion Studies (pp. 159-163). London: Bloomsbury.

Scher, R. (2013). Exploring green house core values: Real home. The Green House Project Blog. Available on: http://changingaging.org/blog/ exploring-green-house-core-values-real-home/ (Accessed: February 07, 2014).

Schiermer, B. (2011). Quasi-objects, cult objects and fashion object: On two kinds of fetishism on display in modern culture. Theory, Culture $\mathcal{E}$ Society 28(1): 81-102.

Simmel, G. (1904/1971). Fashion. In D. C. Levine (ed.), On Individuality and Social Forms: Selected Writings (pp. 294-323). Chicago, IL: University of Chicago Press.

Skeggs, B. (1997). Formations of Class and Gender: Becoming Respectable. London: Sage.

Stirling, J. (1995). Dementia, discourse, difference and denial: 'Who did I become?' Law, Text, and Culture 2(1): 147-159.

Stov, L. (2011). Entering the space of the wardrobe. Creative Encounters Working Papers 58: 2-25.

Tallack, D. (2002). 'Waiting, waiting': The hotel lobby, in the modern city. In N. Leach (ed.), The Hieroglyphics of Space: Reading and Experiencing the Modern Metropolis (pp. 139-151). London: Routledge. 
Tönnies, F. (1887/2004). Custom: An essay on social codes. In D. L. Purdy (ed.), The Rise of Fashion: A Reader (pp. 333-340). Minnesota: University of Minnesota Press.

Tseëlon, E. (1995). The Masque of Femininity. London: Sage.

Twigg, J. (2000). Bathing - The Body and Community Care. London: Routledge.

Twigg, J. (2010). Clothing and dementia: A neglected dimension? Journal of Aging Studies 24(4): 223-230.

Twigg, J. (2013). Fashion and Age: Dress, the Body and Later Life. Oxford: Berg.

Twigg, J. \& Martin, W. (eds.). (2015). The Routledge Handbook of Cultural Gerontology. London: Routledge.

Veblen, T. (1899/1994). Theory of the Leisure Class. London: Dove.

Verbeek, H., Rossum, E., Zwakhalen, S. M. G., Kempen, G. I. J. M. \& Hamers, J. P. H. (2009). Small, homelike care environments for older people with dementia: A literature review. International Psychogeriatrics 21(2): 252-264.

Ward, R., Vass, A. A., Aggarwal, N., Garfield, C. \& Cybyk, B. (2008). A different story: Exploring patterns of communication in residential dementia care. Ageing $\mathcal{E}$ Society 28: 629-651.

Weber, S. \& Mitchell, C. (2004). Not Just Any Dress: Narratives of Memory, Body and Identity. New York: Peter Lang.

Woodward, K. M. (1999). Introduction. In K. M. Woodward (ed.), Figuring Age: Women, Bodies and Generations (pp. ix-xxix). Bloomington: Indiana University Press.

Woodward, K. M. (2006). Performing age, performing gender. National Women's Studies Association (NWSA) Journal 18(1): 162-189.

Woodward, S. (2007). Why Women Wear What They Wear. Oxford: Berg.

Wiersma, E. \& Dupuis, S. L. (2010). Becoming institutional bodies: Socialization into a long-term care home. Journal of Aging Studies 24(4): 278-291.

Yarnal, C., Son, J. \& Liechty, T. (2011). She was buried in her purple dress and her red hat and all of our members wore full 'Red Hat Regalia' to celebrate her life": Dress, embodiment and older women's leisure: Reconfiguring the ageing process. Journal of Aging Studies 25(1): 52-61. 